\title{
Radiological Diagrinosis
}

\section{We ask: What is the diagnosis?}

\section{Dany Jasinowodolinski ${ }^{1}$, Gustavo de Souza Portes Meirelles², Flavio Duarte Silva ${ }^{3}$, Nestor L Müller}

A 20-year-old female patient reporting fever and joint pain for 3 months. Complementary tests: Positivity for anti-nuclear factor (ANF), anemia ( $\mathrm{Hb}: 8.7)$ and leucopenia. Chest $\mathrm{X}$-ray revealed a nodule.
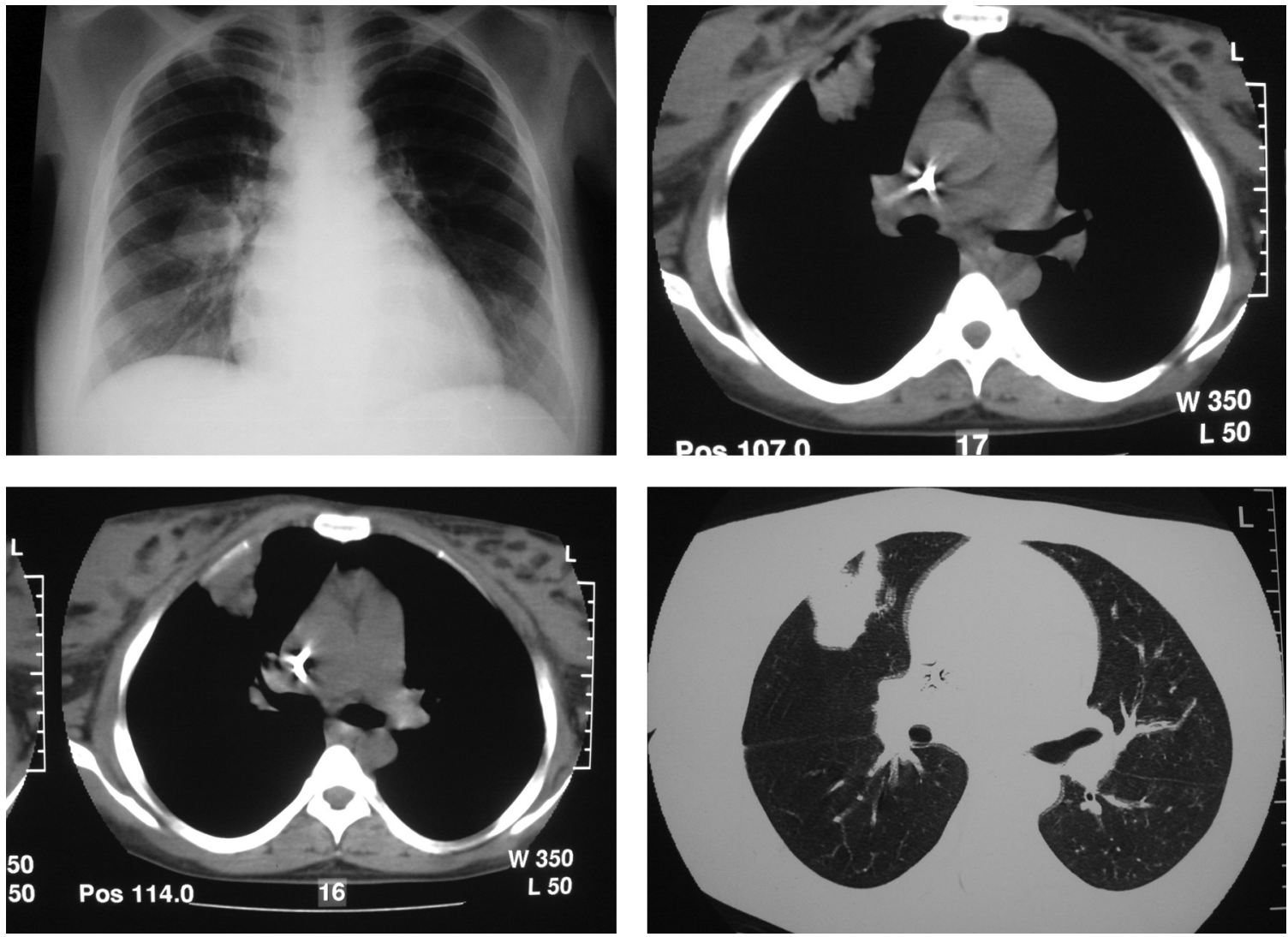

This section is intended to encourage a diagnostic approach based on clinical and radiological findings. We invite all of our readers to participate.

Submit your diagnosis by completing the form you will find on our website (www.jornaldepneumologia.com.br) or by sending an e-mail to jpneumo@terra.com.br. Remember to include the full name of your institution. The diagnosis for this case, along with the names of readers who submitted correct responses, will be published in the next issue of the journal. The images shown here are those that were most relevant in making the final diagnosis.

1. Radiologist at the Fleury Center for Diagnostic Medicine, São Paulo, Brazil.

2. PhD in Radiology from the Universidade Federal de São Paulo (UNIFESP, Federal University of São Paulo) - São Paulo, Brazil.

3. Resident in Radiology in the Universidade Federal de São Paulo (UNIFESP, Federal University of São Paulo) - São Paulo, Brazil .

4. Full Professor of Radiology at the University of British Columbia, Vancouver, British Columbia, Canada. 